\title{
Size Controlled Synthesis of Germanium Nanocrystals: Effect of Ge Precursor and Hydride Reducing Agent
}

\author{
Darragh Carolan and Hugh Doyle \\ Tyndall National Institute, University College Cork, Lee Maltings, Cork, Ireland \\ Correspondence should be addressed to Hugh Doyle; hugh.doyle@tyndall.ie
}

Received 17 March 2015; Revised 2 May 2015; Accepted 2 May 2015

Academic Editor: Christian Brosseau

Copyright ( 2015 D. Carolan and H. Doyle. This is an open access article distributed under the Creative Commons Attribution License, which permits unrestricted use, distribution, and reproduction in any medium, provided the original work is properly cited.

\begin{abstract}
Germanium nanocrystals (Ge NCs) have attracted increasing attention as a promising alternative to II-VI and IV-VI semiconductor materials as they are cheap, "green," electrochemically stable, and compatible with existing CMOS processing methods. Germanium is a particularly attractive material for optoelectronic applications as it combines a narrow band gap with high carrier mobilities and a large exciton Bohr radius. Solution-phase synthesis and characterisation of size monodisperse alkylterminated Ge NCs are demonstrated. Ge NCs were synthesised under inert atmospheric conditions via the reduction of Ge halide salts $\left(\mathrm{GeX}_{4}\right)$ by hydride reducing agents within inverse micelles. Regulation of NC size is achieved by variation of germanium precursor and the strength of hydride reducing agents used. UV-Visible absorbance and photoluminescence spectroscopy showed strong significant quantum confinement effects, with moderate absorption in the UV spectral range, and strong emission in the violet with a marked dependence on excitation wavelength.
\end{abstract}

\section{Introduction}

Over the last 25 years, the size dependant optical and electrical properties of semiconductor nanocrystals (NCs) have attracted extensive research into methods to control their size, shape, composition, and surface chemistry $[1,2]$. While II-VI and III-V nanomaterials offer facile spectral tuning, high quantum yields, and excellent photostability, concerns about their potential toxicity exist due to their heavy metal content $[3,4]$. Germanium is an attractive alternative for optoelectronic applications as it combines a narrow band gap $(0.67 \mathrm{eV})$ and high carrier mobilities $\left(\mu_{e}=3900 \mathrm{~cm}^{2} \mathrm{~V}^{-1} \mathrm{~s}^{-1}\right.$, $\mu_{h}=1900 \mathrm{~cm}^{2} \mathrm{~V}^{-1} \mathrm{~s}^{-1}$ ) with a large absorption coefficient ( $c$. $2 \times 10^{5} \mathrm{~cm}^{-1}$ ) and exciton Bohr radius (24 nm) [5-7]. Besides its compatibility with current microelectronics processing methods, germanium is also nontoxic, electrochemically stable, and relatively inexpensive [8]. However, the majority of the application areas currently being considered, including chemical sensing [9], field effect transistors [10], and photodetectors [11], require the preparation of Ge NCs in good yield with narrow size distributions and well characterized surface chemistry, as these define many of their photophysical properties.

A number of different synthetic approaches have been investigated towards achieving this objective, including the metathesis reaction of $\mathrm{GeCl}_{4}$ with Zintl salts $[12,13]$, reduction of $\mathrm{NaGe}$ by ammonium bromide [14], and high temperature decomposition of organogermane precursors [15-17]. Other methods include thermal coreduction of $\mathrm{Ge}(\mathrm{II})$ and amido based precursors $[18,19]$, aqueous phase reduction of $\mathrm{GeO}_{2}$ powders by $\mathrm{NaBH}_{4}$ [20], and other high temperature chemical reduction methods [21-25]. Disadvantages associated with these methods include lengthy precursor synthesis, long reaction times, high temperatures and pressures, and extensive postsynthetic purification procedures $[8,23]$.

The use of microemulsion based synthetic methods has been the most promising due to their ability to control the size, shape, and surface chemistry of Ge NCs. Wilcoxon et al. reported room temperature synthesis of 3-11 nm diameter Ge NCs within reverse micelles via reduction of germanium halide precursors $\mathrm{GeX}_{4}\left(X=\mathrm{Cl}, \mathrm{Br}\right.$, or I) with $\mathrm{LiAlH}_{4}$ [26]. Fok et al. later produced hydride-terminated Ge NCs 


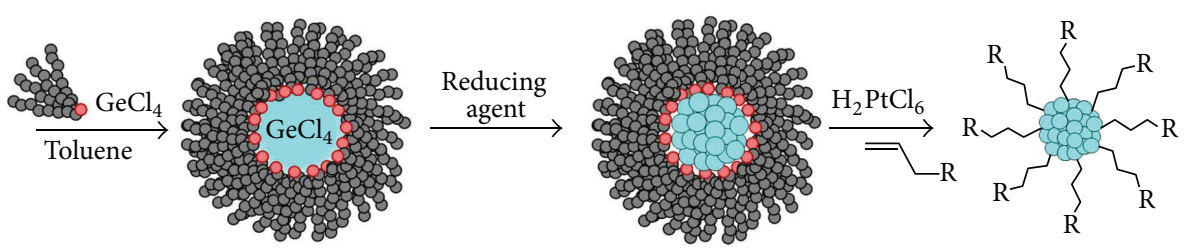

Scheme 1: Reaction scheme for synthesis of alkyl-terminated Ge NCs.

with an average diameter of $5 \mathrm{~nm}$ via reduction of $\mathrm{GeI}_{4}$ with $\mathrm{LiAlH}_{4}$ using cetyltrimethylammonium bromide (CTAB) as a surfactant [27]. Subsequent modification of the NC surface by thermally initiated hydrogermylation resulted in alkylterminated NCs. Warner and Tilley prepared size monodisperse $5 \mathrm{~nm}$ Ge NCs by reducing $\mathrm{GeCl}_{4}$ within tetraoctylammonium bromide (TOAB) micelles, modifying the surface of the as-synthesized Ge NCs using a Pt-catalysed hydrogermylation reaction to form amine-terminated NCs with covalent Ge-C bonds. This surface modification strategy chemically passivates the nanocrystal surface to prevent oxidation [28]. Prabakar and coworkers later examined the formation of $\mathrm{Ge}$ NCs using a series of metal hydrides to reduce $\mathrm{GeCl}_{4}$ within pentaethylene glycol monododecyl ether $\left(\mathrm{C}_{12} \mathrm{E}_{5}\right)$ micelles at room temperature [29].

Previously, we reported the synthesis of size monodisperse Ge NCs using a room temperature microemulsion strategy $[30,31]$. The surfaces are terminated with a covalently attached monolayer, chemically passivating the surface and allowing for the NCs to be dispersed in a variety of polar solvents; see Scheme 1. Here we report a simple room temperature method for the size controlled synthesis of alkylterminated Ge NCs, using different germanium precursors and hydride reducing agents of different strengths to control the $\mathrm{NC}$ core diameter between 2 and $10 \mathrm{~nm}$.

\section{Experimental}

2.1. Materials. Sulphuric acid (95-97\%), hydrogen peroxide $(30 \% \mathrm{v} / \mathrm{v})$, hexane (CHROMASOLV grade, $\geq 97.0 \%)$, and $n$-methyl formamide (99\%) were purchased from SigmaAldrich Ltd. and stored under ambient atmosphere. Germanium tetrachloride $\left(\mathrm{GeCl}_{4}, 99.99 \%\right)$, germanium tetrabromide $\left(\mathrm{GeBr}_{4}\right)$, tetraoctylammonium bromide (TOAB, $98 \%)$, lithium aluminium hydride $\left(\mathrm{LiAlH}_{4}, 1 \mathrm{M}\right.$ in THF), lithium triethylborohydride $\left(\mathrm{Li}\left(\mathrm{C}_{2} \mathrm{H}_{5}\right)_{3} \mathrm{BH}, 1 \mathrm{M}\right.$ in THF), lithium borohydride $\left(\mathrm{LiBH}_{4}, 2 \mathrm{M}\right.$ in THF), lithium tri-secbutylborohydride $\left(\mathrm{Li}\left[\mathrm{CH}\left(\mathrm{CH}_{3}\right) \mathrm{CH}_{2} \mathrm{CH}_{3}\right]_{3} \mathrm{BH}, 1 \mathrm{M}\right.$ in THF), chloroplatinic acid hexahydrate $\left(\mathrm{H}_{2} \mathrm{PtCl}_{6},>37.5 \% \mathrm{Pt}\right.$ basis $)$, allylamine $(\geq 99 \%)$, 1-heptene $(97 \%)$, propan-2-ol $(99.5 \%$, anhydrous), toluene (99.8\%, anhydrous), and methanol (99.8\%, anhydrous) were purchased from Sigma-Aldrich Ltd. and stored under inert atmosphere before use. All materials and solvents were used as received.

2.2. Preparation of Ge Nanocrystals. All synthetic manipulations were carried out in an inert atmosphere glove box, with water and oxygen levels kept below $0.1 \mathrm{ppm}$ in order to prevent simple hydrolysis of the Ge precursor. Glassware was cleaned by soaking in a base bath overnight, followed by immersion in piranha solution $(3: 1$ concentrated sulphuric acid : $30 \%$ hydrogen peroxide) for 20 minutes. In a typical preparation, $2.74 \mathrm{mmol}$ of the surfactant was dissolved in $60 \mathrm{~mL}$ toluene in a 2-neck round bottomed flask with continuous stirring. $0.876 \mathrm{mmol}$ of the germanium precursor $\left(\mathrm{GeCl}_{4}\right.$ or $\left.\mathrm{GeBr}_{4}\right)$ was then added to the solution and left to stir for $30 \mathrm{~min}$. Ge NCs were formed by the dropwise addition of $2 \mathrm{~mL}$ of the hydride reducing agent over 2 minutes. The solution was then left to stir for $2.5 \mathrm{~h}$. The excess reducing agent was then quenched with $20 \mathrm{~mL}$ methanol. The Ge NC surfaces were modified by addition of $100 \mu \mathrm{L}$ of chloroplatinic acid hexahydrate $(0.1 \mathrm{M}$ in propan-2-ol), followed by $2 \mathrm{~mL}$ 1-heptene. The Ge NCs were removed from the glove box and the organic solvent was removed by rotary evaporation, yielding a pale yellow powder or oil consisting of TOAB and Ge NCs. The alkyl-terminated NCs were extracted with hexane and filtered first with filter paper and then with PTFE syringe filters $(0.45 \mu \mathrm{m}$, Acrodisc) to remove all large aggregates. The NCs were washed three times with $100 \mathrm{~mL}$ of $n$-methyl formamide and then with $100 \mathrm{~mL}$ deionised water $(18.2 \mathrm{M} \Omega \mathrm{cm})$.

2.3. Characterisation. Transmission electron microscopy (TEM) images and selective area electron diffraction (SAED) patterns were acquired using a high-resolution JEOL 2100 electron microscope, equipped with ${\mathrm{a} \mathrm{LaB}_{6}}_{6}$ thermionic emission filament and Gatan DualVision 600 Charge-Coupled Device (CCD), operating at an accelerating voltage of $200 \mathrm{keV}$. Data for size distribution histograms was acquired by analysis of TEM images of ca. $300 \mathrm{NCs}$ located at different regions of the grid. NC diameter was determined by manual inspection of the digital images; in the case of anisotropic structures, the diameter was determined using the longest axis. UV-Vis absorbance spectra were acquired using an Agilent 8453 spectrometer or a Shimadzu UV PC2401 spectrophotometer equipped with a $60 \mathrm{~mm}$ integrating sphere (ISR-240A, Shimadzu). Photoluminescence (PL) spectra were recorded on a Perkin Elmer LS 50B luminescence spectrometer. All optical spectra were recorded at room temperature using a quartz cuvette $(1 \mathrm{~cm})$ and corrected for the solvent absorption. FTIR measurements were performed on a Bio Rad Excalibur FTS 3000 spectrometer. Samples were drop-cast onto a $32 \mathrm{~mm}$ round, $3 \mathrm{~mm}$ thick, drilled $\mathrm{NaCl}$ plate and left to dry in air. 


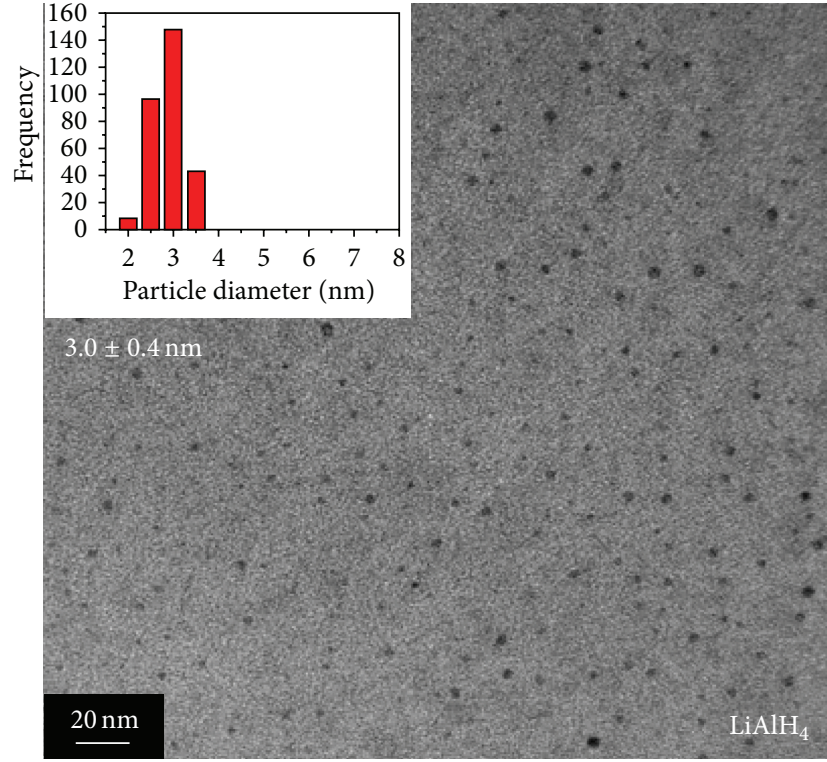

(a)
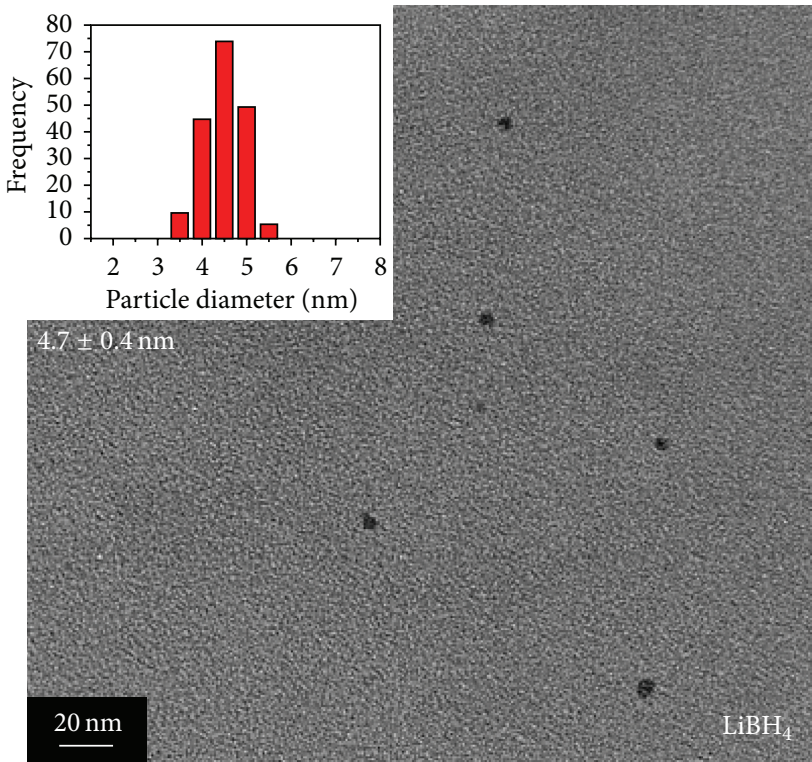

(c)
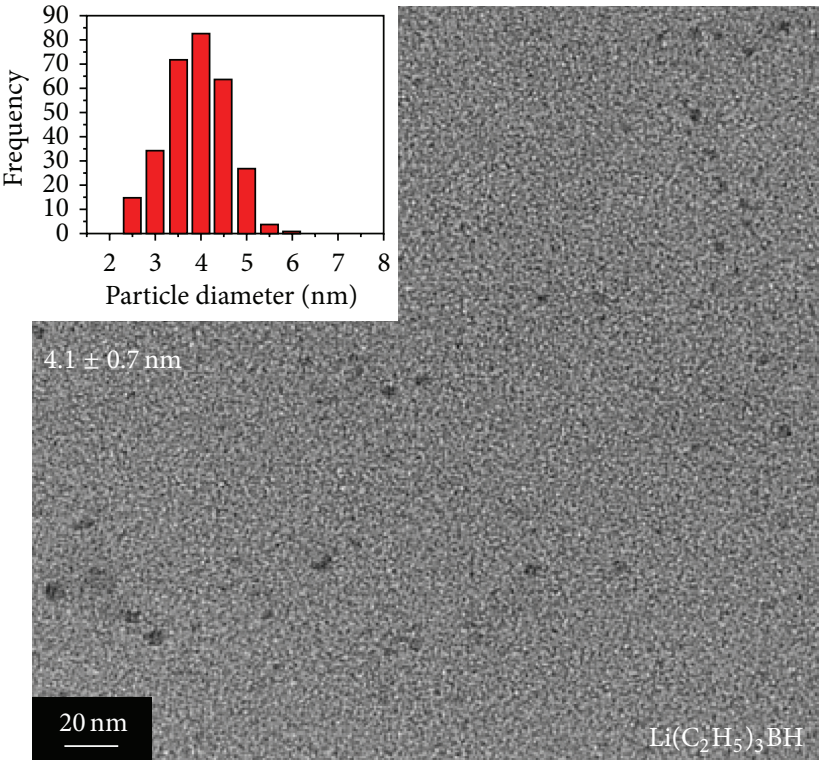

(b)
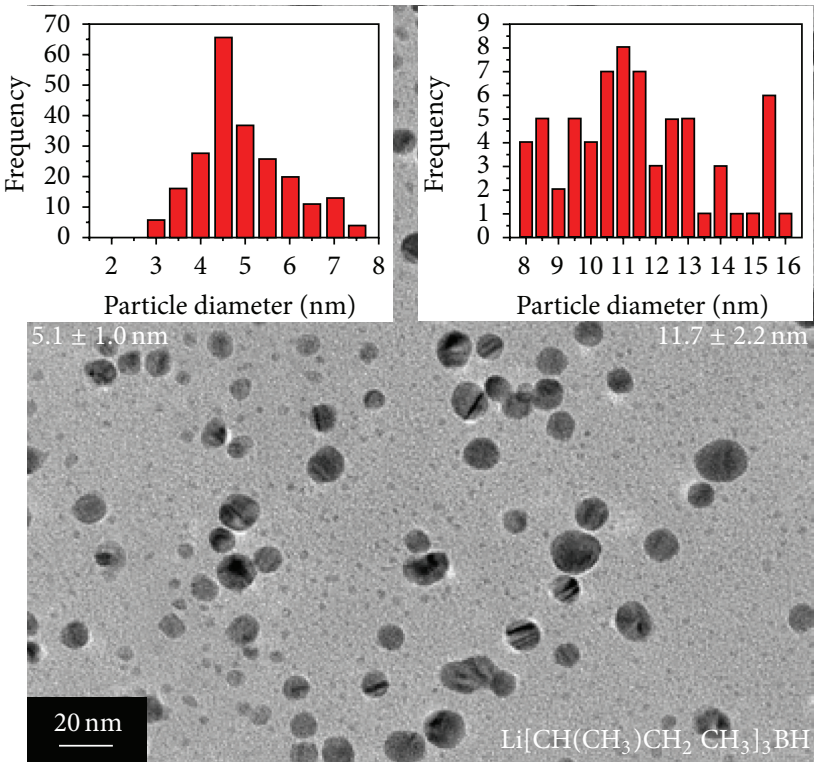

(d)

Figure 1: TEM images of Ge NCs prepared by the reduction of $\mathrm{GeCl}_{4}$ by (a) $\mathrm{LiAlH}_{4}$, (b) $\mathrm{Li}_{\left(\mathrm{C}_{2} \mathrm{H}_{5}\right)_{3} \mathrm{BH},(\mathrm{c}) \mathrm{LiBH}}$, and $(\mathrm{d}) \mathrm{Li}\left[\mathrm{CH}\left(\mathrm{CH}_{3}\right)\right.$ $\left.\mathrm{CH}_{2} \mathrm{CH}_{3}\right]_{3} \mathrm{BH}$. Inset: size histograms of the Ge NCs.

\section{Results and Discussion}

Alkyl-terminated Ge NCs were synthesized under inert atmosphere conditions by room temperature reduction of $\mathrm{GeCl}_{4}$ or $\mathrm{GeBr}_{4}$ by hydride reducing agents of different reactivities: lithium aluminium hydride $\left(\mathrm{LiAlH}_{4}\right)$, lithium triethylborohydride (Superhydride, $\mathrm{Li}\left(\mathrm{C}_{2} \mathrm{H}_{5}\right)_{3} \mathrm{BH}$ ), lithium borohydride $\left(\mathrm{LiBH}_{4}\right)$, and lithium tri-sec-butylborohydride (L-Selectride, $\left.\mathrm{Li}\left(\mathrm{CH}\left(\mathrm{CH}_{3}\right) \mathrm{CH}_{2} \mathrm{CH}_{3}\right)_{3} \mathrm{BH}\right)$. Figure 1 shows bright field transmission electron microscope (TEM) images of $\mathrm{Ge}$ NCs prepared from $\mathrm{GeCl}_{4}$ with the different hydride reducing agents. TEM imaging of Ge NCs synthesized in the presence of the strongest reducing agent $\mathrm{LiAlH}_{4}$ (Figure 1(a)) shows that the Ge NCs are highly size and shape monodisperse, with no evidence of aggregation. Inset in Figure 1(a) is a histogram of Ge NC diameters, determined by analysis of TEM images of $300 \mathrm{Ge}$ NCs located at random locations on the grid. Fitting the histogram to a Gaussian model yielded a mean diameter of $3.0 \mathrm{~nm}$, with a standard deviation of $0.4 \mathrm{~nm}$. Replacing $\mathrm{LiAlH}_{4}$ with Superhydride or $\mathrm{LiBH}_{4}$ resulted in an increase in the mean diameter to $4.1 \pm 0.7 \mathrm{~nm}$ and $4.7 \pm 0.4 \mathrm{~nm}$, respectively; see Figures 1 (b) and 1 (c). These findings are in good agreement with the results reported by Prabakar et al. [29], who reported a similar relationship 

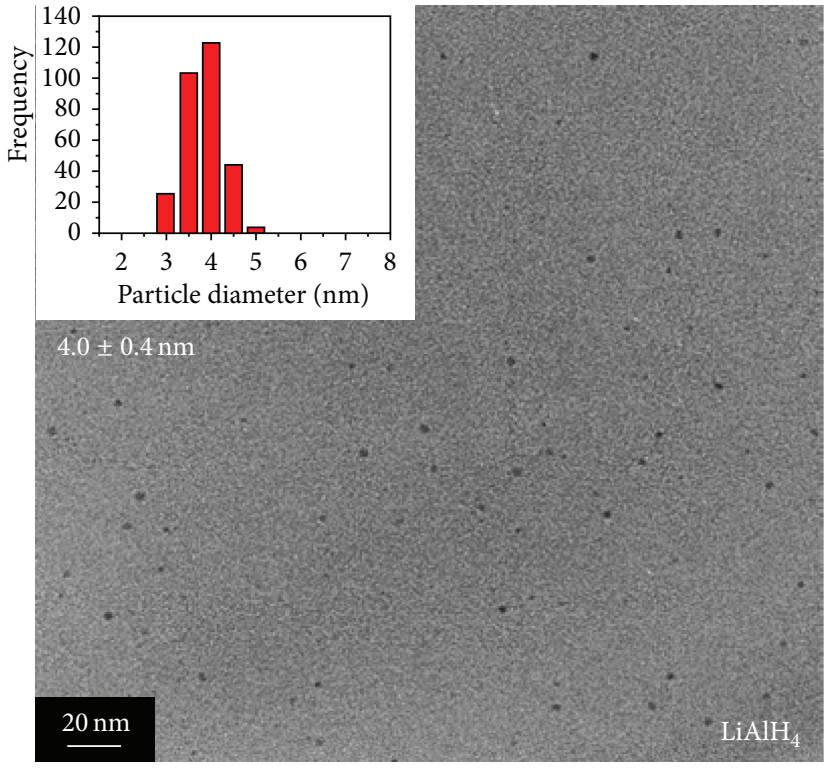

(a)
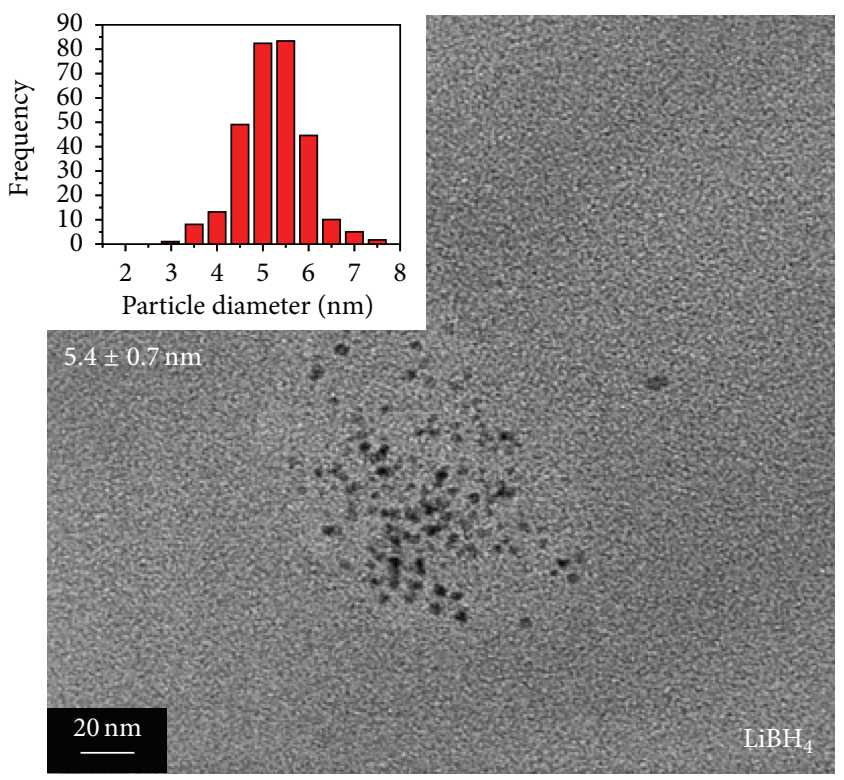

(c)
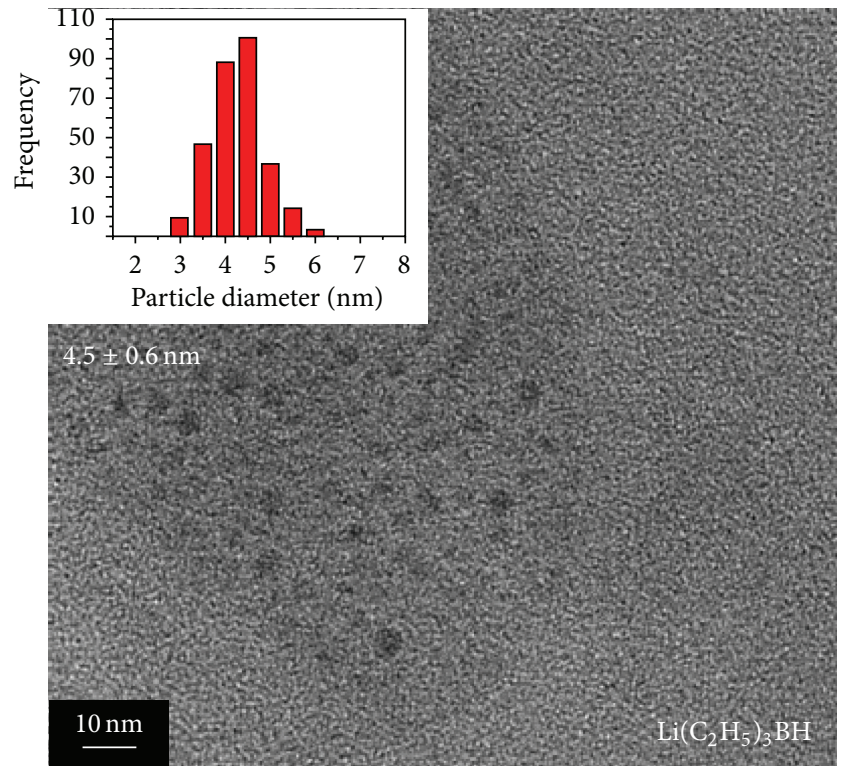

(b)
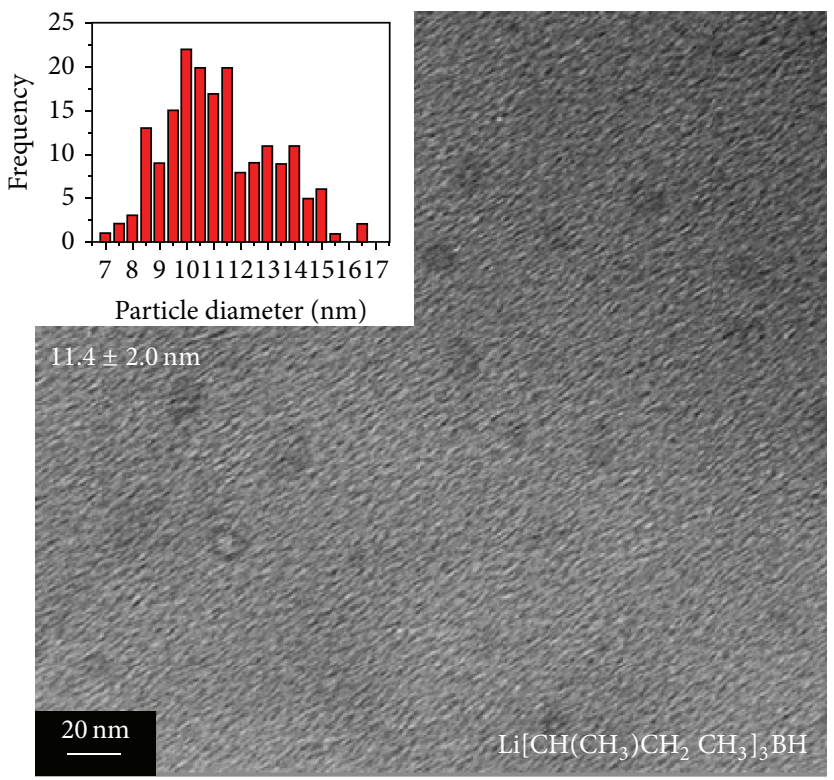

(d)

Figure 2: TEM images of Ge NCs prepared by the reduction of $\mathrm{GeBr}_{4}$ by (a) $\mathrm{LiAlH}_{4}$, (b) $\mathrm{Li}_{\left(\mathrm{C}_{2} \mathrm{H}_{5}\right)_{3} \mathrm{BH},(\mathrm{c}) \mathrm{LiBH}}$, and $(\mathrm{d}) \mathrm{Li}\left[\mathrm{CH}\left(\mathrm{CH}_{3}\right)\right.$ $\left.\mathrm{CH}_{2} \mathrm{CH}_{3}\right]_{3} \mathrm{BH}$. Inset: size histograms of the Ge NCs.

between Ge NC size and the hydride reducing agent used. LSelectride produced a bimodal size distribution, with $5.1 \pm$ $1.0 \mathrm{~nm}$ and $11.7 \pm 2.2 \mathrm{~nm}$ Ge NCs formed; see Figure 1(d). These results may be interpreted in terms of the relative strength of the hydride reducing agents used. As the most powerful reducing agent, $\mathrm{LiAlH}_{4}$ causes rapid consumption of $\mathrm{GeCl}_{4}$ during the initial burst nucleation phase, resulting in small, size monodisperse Ge NCs. Superhydride and $\mathrm{LiBH}_{4}$ also yield size monodisperse NCs, but their lower reactivity leads to slightly larger nanocrystals. The sterically hindered LSelectride consumes the least amount of precursor during the nucleation phase, leaving more precursor material remaining for subsequent diffusional growth in solution, resulting in larger and more polydisperse nanocrystals.

A similar relationship between size and reducing agent was observed for Ge NCs synthesised with $\mathrm{GeBr}_{4}$; see Figure $2 . \mathrm{LiAlH}_{4}$ produced the smallest and most monodisperse NCs, with a mean diameter of $4.0 \mathrm{~nm}$ and a standard deviation of $0.4 \mathrm{~nm}$. Superhydride $(4.5 \pm 0.6 \mathrm{~nm})$ and $\mathrm{LiBH}_{4}(5.4 \pm$ $0.7 \mathrm{~nm}$ ) produced larger NCs, while the most polydisperse samples $(11.4 \pm 2.0 \mathrm{~nm})$ were formed with L-Selectride. Comparison of NCs synthesised with different precursor under otherwise identical reaction conditions showed that nanocrystals prepared with $\mathrm{GeBr}_{4}$ were up to $30 \%$ larger 


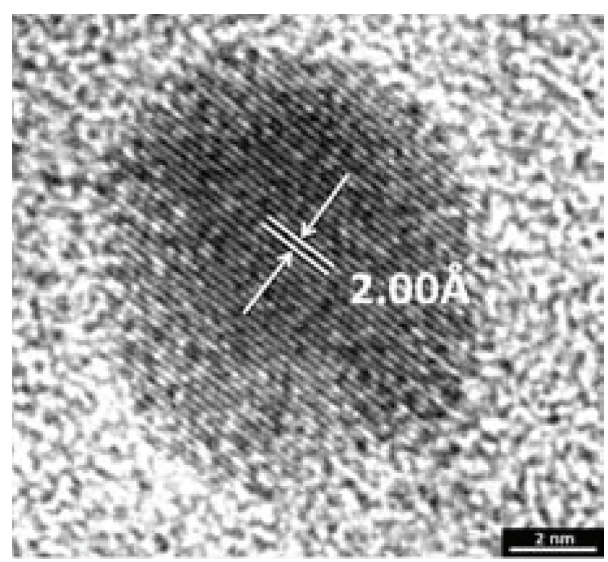

(a)

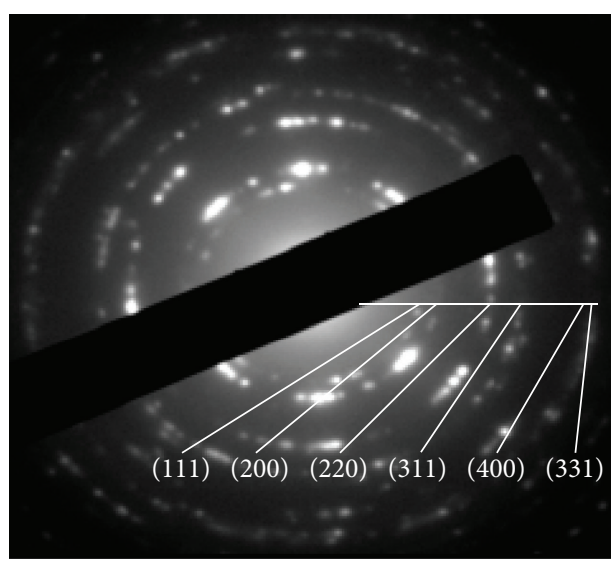

(b)

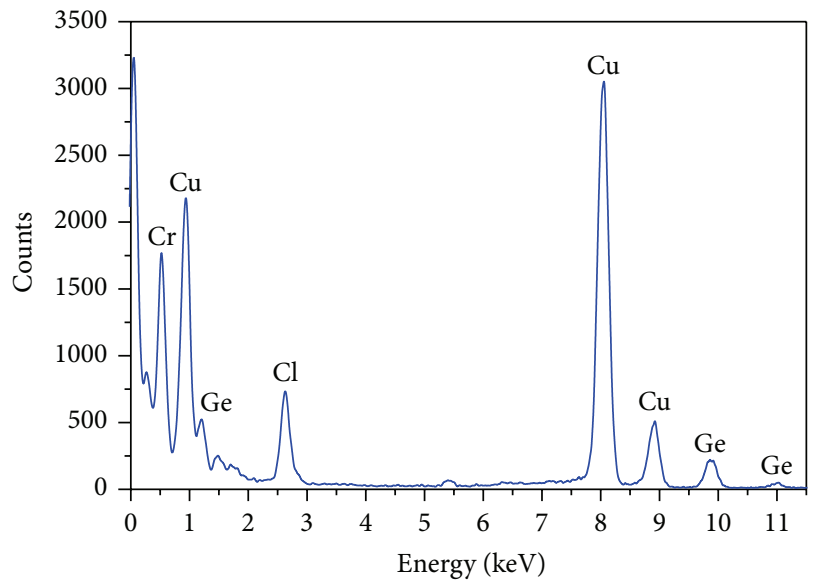

(c)

FIGURE 3: (a) HR-TEM of an individual Ge NC with the distance between lattice planes indicated, (b) SAED pattern, and (c) EDX spectrum of the Ge NCs.

than those prepared with $\mathrm{GeCl}_{4}$. It is known that, in microemulsion based syntheses of metal and semiconductor nanocrystals, the size and shape of the micellar template and thus the resultant crystallite are significantly influenced by precursor anions in accordance with the Hofmeister series [32-34]. These anion effects, allied to the lower Ge-Br bond strength and the greater leaving group ability of the bromide ion, would account for the differences observed.

High-resolution TEM (HR-TEM) imaging was used along with selective area electron diffraction (SAED) to confirm the crystallinity and establish the crystal phase of the NCs; see Figures 3(a) and 3(b). HR-TEM imaging (Figure 3(a)) showed that the Ge NCs form a continuous crystalline phase, without the presence of packing defects. The lattice fringes shown in Figure 3(a) correspond to a d spacing of $2.0 \AA$, matching the (220) spacing reported for the germanium unit cell. SAED patterns of the $\mathrm{Ge}$ NCs (Figure 3(b)) showed reflections that could be indexed to $\mathrm{Ge}$ diamond cubic (Fd3m) lattice at $3.3 \AA$ (111), $2.0 \AA$ (220), $1.7 \AA$ (311), $1.3 \AA$ (331), and $1.2 \AA$ (422), respectively. EDX spectroscopy was employed to determine the elemental composition of the samples. Figure 3(c) shows the energy dispersive X-ray (EDX), where the Ge peaks due to the nanocrystals are clearly seen. $\mathrm{Cl}$ and $\mathrm{Cu}$ peaks are due to synthetic byproducts and the copper grid support, respectively.

The Ge NC surface chemistry was characterised by FTIR spectroscopy; see Figure 4. The peaks from $3000-2850 \mathrm{~cm}^{-1}$ are attributed to the $\mathrm{CH}_{3}$ and $\mathrm{CH}_{2}$ stretching modes of the alkyl chain [31]. The peaks at 1458 and $1260 \mathrm{~cm}^{-1}$ are ascribed to the scissoring and bending of the $\mathrm{Ge}-\mathrm{C}$ and $\mathrm{Ge}-\mathrm{CH}_{2}$ bonds, respectively, while the strong peak at $1375 \mathrm{~cm}^{-1}$ is assigned to the $\mathrm{C}-\mathrm{CH}_{3}$ symmetric stretching mode [31]. The absence of the characteristic alkene peaks at 3080 and $1640 \mathrm{~cm}^{-1}$, combined with the $\mathrm{Ge}-\mathrm{C}$ and $\mathrm{Ge}-\mathrm{CH}_{2}$ peaks, confirms the presence of surface-bound heptyl groups. The Ge-OR and the Ge-C stretching modes below $1100 \mathrm{~cm}^{-1}$ are consistent with a covalently attached alkyl layer with some surface oxidation $[12,30,31]$. No significant increase in the intensity of these peaks is observed after storage under ambient conditions, indicating that the NCs are resistant to further oxidation.

The optical properties of the Ge NCs were investigated using UV-Vis absorbance and photoluminescence (PL) spectroscopy. Figure 5 shows the UV-Vis absorption spectrum of 


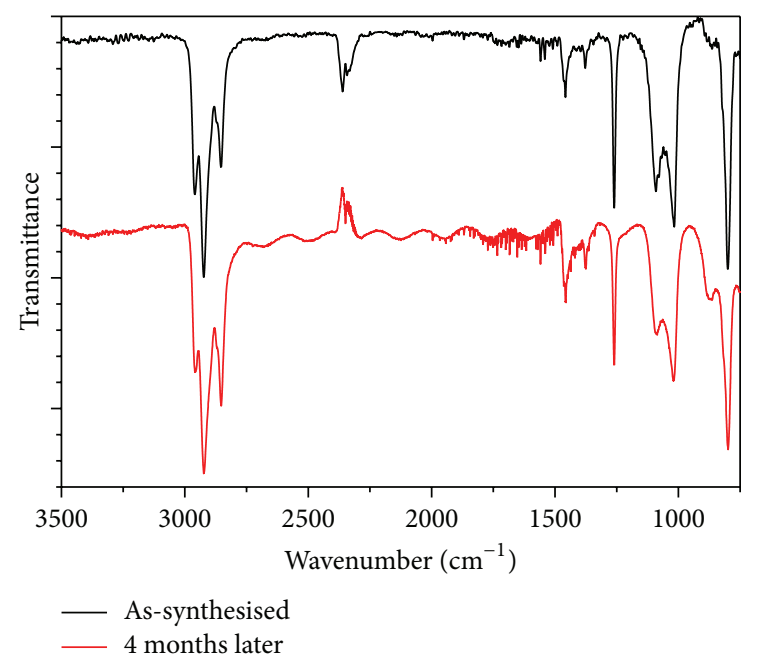

FIGURE 4: FTIR spectra of the as-synthesised (black curve) heptylterminated Ge NCs and the same NC dispersion 4 months afterwards (red curve).

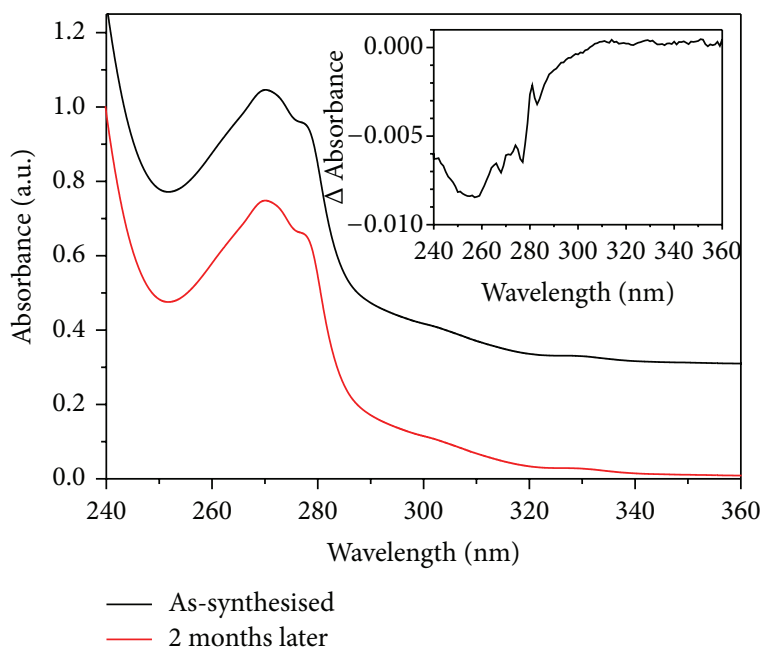

Figure 5: UV-Vis absorbance spectra of as-synthesised Ge NCs (black curve) and after storage for 2 months (red curve). Spectra have been offset for clarity. Inset: change in the absorbance spectrum between measurements.

Ge NCs prepared using $\mathrm{GeCl}_{4}$ and $\mathrm{LiAlH}_{4}$, although similar spectra were obtained for all the nanocrystals reported here. The spectrum shows evidence of strong quantum confinement effects, with a broad absorbance centred at $270 \mathrm{~nm}$ with a shoulder at $278 \mathrm{~nm}$, and the presence of a weaker second peak at ca. $330 \mathrm{~nm}$, close to the onset of absorbance at ca. $350 \mathrm{~nm}(3.5 \mathrm{eV})$. Similar spectral features have been previously reported in optical spectra of Ge NCs, which were assigned to direct transitions from $\Gamma_{25}$ to split energy levels at $\Gamma_{15}[26,35]$. The significant blue shift in the onset of absorption compared to the bulk Ge band gap energy $(0.6 \mathrm{eV})$ suggests the presence of quantum confined carriers in the nanocrystals. The UV-Vis spectrum recorded 2 months later showed only a small drop in absorbance (see the inset in
Figure 4), indicating that the NCs are stable under ambient lighting and atmospheric conditions.

Figures 6(a) and 6(b) show the PL spectra $(280 \mathrm{~nm}$ excitation) of hexane dispersions of the heptyl-terminated Ge NCs prepared using $\mathrm{GeCl}_{4}$ and $\mathrm{GeBr}_{4}$ precursors, respectively. All Ge NCs exhibited a structured luminescence over a narrow spectral range $(300-450 \mathrm{~nm})$, with a peak near $330 \mathrm{~nm}$ $(3.75 \mathrm{eV})$, similar to previous reports for alkyl-terminated $\mathrm{Ge}$ NCs of similar size [31]. While the luminescence intensity decreases with increasing nanocrystal diameter, as would be expected due to the greater contribution of nonradiative exciton recombination pathways, there is no change in the PL spectra, in agreement with our previous results for heptylterminated Si NCs prepared using the same synthetic strategy [36]. This size independence implies that exciton recombination is not wholly confined within the nanocrystalline core and that the PL mechanism involves surface states $[31,36]$, such as the $\mathrm{Ge}-\mathrm{O}_{x}$ surface species previously identified (see Figure 4).

All the NC dispersions show a strong dependence between the wavelength position of the PL maximum and the excitation wavelength; see Figure 6(c). Excitation energies for peak PL intensity $(4.4 \mathrm{eV})$ are considerably higher than the absorption edge $(3.5 \mathrm{eV})$, with a marked dependence between luminescence intensity and excitation wavelength. The wavelength position of the PL maximum red-shifts from $330 \mathrm{~nm}$ to $424 \mathrm{~nm}$ as the excitation wavelength is increased from $280 \mathrm{~nm}$ to $400 \mathrm{~nm}$; see Figures 6(c) and 6(d). This corresponds to an overall red shift in the PL peak position of $94 \mathrm{~nm}$ as the excitation wavelength is increased by $120 \mathrm{~nm}$; see Figure 6(d). Increasing the excitation wavelength also results in over a 10-fold decrease in the PL intensity; see also Figure 6(d). These trends are observed in PL spectra for all Ge NCs synthesised.

This excitation wavelength dependence has been observed by a number of groups for alkyl-terminated $\mathrm{Ge}$ NCs $[8,12,14,15,18,31,36]$, which has been attributed to the involvement of various surface states in the luminescence process. Dasog et al. unambiguously demonstrated that the blue luminescence in alkyl-terminated Si NCs is due to radiative centres created by nitrogen impurities at the NC surface that provide alternative recombination routes to an indirect bandgap transition [37]. The changes in PL intensity are most likely due to efficient exciton generation at shorter wavelengths, which readily transfer to and recombine at surface states. Excitation at longer wavelengths should result in less efficient exciton generation, which combined with increased transfer to nonradiative trap states, would account for the overall decrease in PL intensity.

\section{Conclusions}

Solution-phase synthesis and characterisation of size monodisperse heptyl-terminated Ge NCs under inert atmospheric conditions have been demonstrated. Control of Ge NC size was achieved by using germanium precursor with different reactivities and changing the strength of hydride reducing agents used. HR-TEM and SAED 


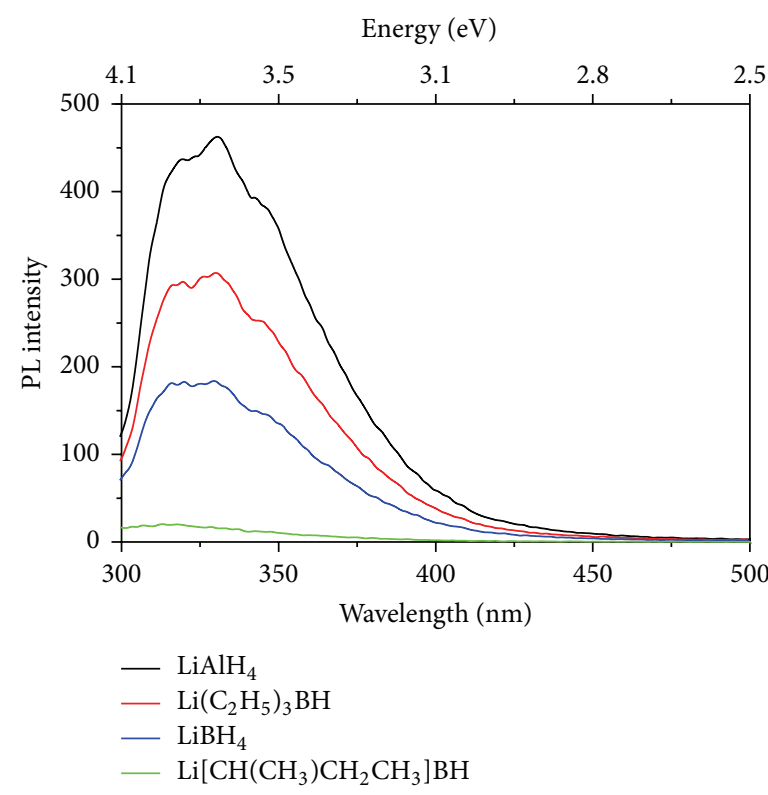

(a)

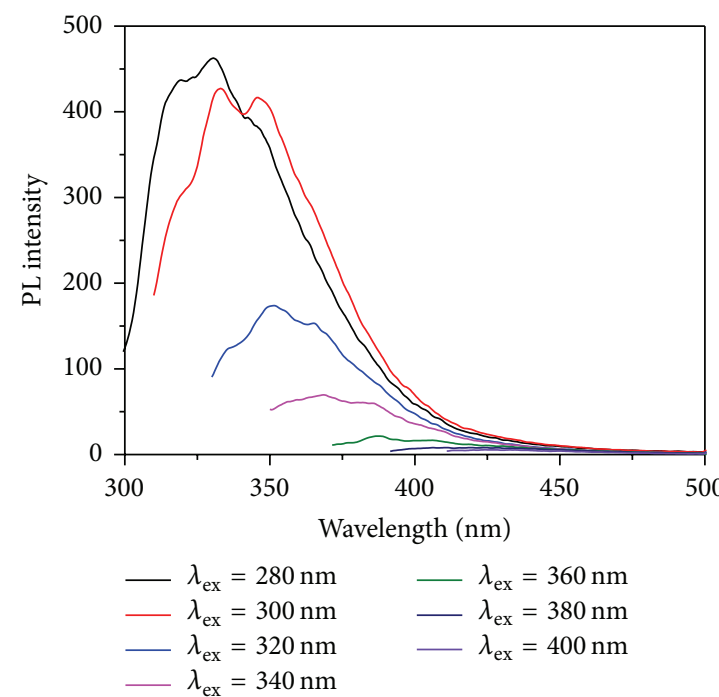

(c)

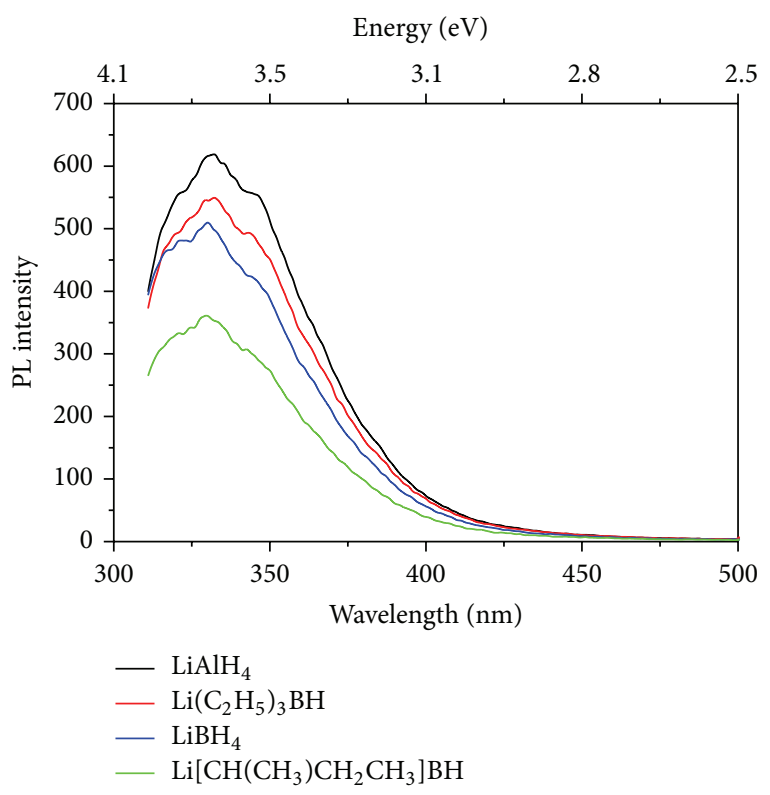

(b)

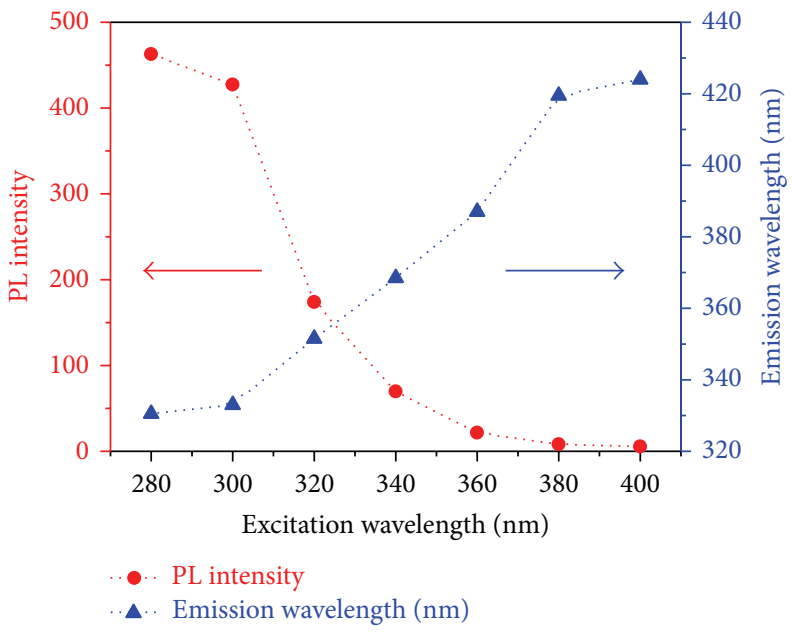

(d)

FIGURE 6: (a) Photoluminescence spectra of Ge NCs synthesised by reduction of $\mathrm{GeCl}_{4}$ by the various hydride reducing agents. (b) PL spectra of Ge NCs synthesised with $\mathrm{GeBr}_{4}$ under the same reaction conditions. (c) PL spectra of Ge NCs recorded at different excitation wavelengths. (d) PL peak position (blue triangles) and intensity (red circles) versus excitation wavelength.

confirmed the crystallinity and phase of the NCs while FTIR confirmed that the Ge NCs were well passivated, with some evidence of surface oxidation. UV-Visible absorbance and photoluminescence spectroscopy showed strong significant quantum confinement effects, with moderate absorption in the UV spectral range, and strong emission in the violet, with a marked dependence on excitation wavelength.

\section{Conflict of Interests}

The authors declare that there is no conflict of interests regarding the publication of this paper.

\section{Acknowledgments}

This work was supported by the European Commission under the FP7 Projects COMMONSENSE (Grant Agreement no. 261809) and SNAPSUN (Grant Agreement no. 246310), as well as the Irish Higher Education Authority under the PRTLI programs Cycle 3 "Nanoscience" and Cycle 4 "INSPIRE."

\section{References}

[1] A. L. Rogach, Ed., Semiconductor Nanocrystal Quantum Dots, Springer, Vienna, Austria, 2008. 
[2] G. Schmid, Ed., Nanoparticles, Wiley-VCH, Weinheim, Germany, 2nd edition, 2010.

[3] Y. Zhang, Y. Bai, J. Jia et al., "Perturbation of physiological systems by nanoparticles," Chemical Society Reviews, vol. 43, no. 10, pp. 3762-3809, 2014.

[4] F. M. Winnik and D. Maysinger, "Quantum dot cytotoxicity and ways to reduce it," Accounts of Chemical Research, vol. 46, no. 3, pp. $672-680,2013$.

[5] R. Pillarisetty, "Academic and industry research progress in germanium nanodevices," Nature, vol. 479, no. 7373, pp. 324328, 2011.

[6] Y. Kamata, "High-k/Ge MOSFETs for future nanoelectronics," Materials Today, vol. 11, no. 1-2, pp. 30-38, 2008.

[7] M. Seino, E. J. Henderson, D. P. Puzzo, N. Kadota, and G. A. Ozin, "Germanium nanocrystal doped inverse crystalline silicon opal," Journal of Materials Chemistry, vol. 21, no. 40, pp. 15895-15898, 2011.

[8] D. D. Vaughn II and R. E. Schaak, "Synthesis, properties and applications of colloidal germanium and germanium-based nanomaterials," Chemical Society Reviews, vol. 42, no. 7, pp. 2861-2879, 2013.

[9] D. Carolan and H. Doyle, "Germanium nanocrystals as luminescent probes for rapid, sensitive and label-free detection of $\mathrm{Fe}^{+}$ions ," Nanoscale, vol. 7, no. 12, pp. 5488-5494, 2015.

[10] Z. C. Holman, C.-Y. Liu, and U. R. Kortshagen, "Germanium and silicon nanocrystal thin-film field-effect transistors from solution," Nano Letters, vol. 10, no. 7, pp. 2661-2666, 2010.

[11] D.-J. Xue, J.-J. Wang, Y.-Q. Wang, S. Xin, Y.-G. Guo, and L.-J. Wan, "Facile synthesis of germanium nanocrystals and their application in organic-inorganic hybrid photodetectors," Advanced Materials, vol. 23, no. 32, pp. 3704-3707, 2011.

[12] B. R. Taylor, S. M. Kauzlarich, G. R. Delgado, and H. W. H. Lee, "Solution synthesis and characterization of quantum confined Ge nanoparticles," Chemistry of Materials, vol. 11, no. 9, pp. 2493-2500, 1999.

[13] A. J. Pugsley, C. L. Bull, A. Sella, G. Sankar, and P. F. McMillan, "XAS/EXAFS studies of Ge nanoparticles produced by reaction between $\mathrm{Mg}_{2} \mathrm{Ge}$ and $\mathrm{GeCl}_{4}$," Journal of Solid State Chemistry, vol. 184, no. 9, pp. 2345-2352, 2011.

[14] X. Ma, F. Wu, and S. M. Kauzlarich, "Alkyl-terminated crystalline Ge nanoparticles prepared from NaGe: synthesis, functionalization and optical properties," Journal of Solid State Chemistry, vol. 181, no. 7, pp. 1628-1633, 2008.

[15] X. Lu, K. J. Ziegler, A. Ghezelbash, K. P. Johnston, and B. A. Korgel, "Synthesis of germanium nanocrystals in high temperature supercritical fluid solvents," Nano Letters, vol. 4, no. 5, pp. 969-974, 2004.

[16] N. Zaitseva, Z. R. Dai, C. D. Grant, J. Harper, and C. Saw, "Germanium nanocrystals synthesized in high-boiling-point organic solvents," Chemistry of Materials, vol. 19, no. 21, pp. 5174-5178, 2007.

[17] E. J. Henderson, M. Seino, D. P. Puzzo, and G. A. Ozin, "Colloidally stable germanium nanocrystals for photonic applications,” ACS Nano, vol. 4, no. 12, pp. 7683-7691, 2010.

[18] H. Gerung, S. D. Bunge, T. J. Boyle, C. J. Brinker, and S. M. Han, "Anhydrous solution synthesis of germanium nanocrystals from the germanium(II) precursor $\mathrm{Ge}\left[\mathrm{N}\left(\mathrm{SiMe}_{3}\right)_{2}\right]_{2}$," Chemical Communications, no. 14, pp. 1914-1916, 2005.

[19] T. N. Lambert, N. L. Andrews, H. Gerung et al., "Water-soluble germanium(0) nanocrystals: cell recognition and near-infrared photothermal conversion properties," Small, vol. 3, no. 4, pp. 691-699, 2007.

[20] J. Wu, Y. Sun, R. Zou et al., “One-step aqueous solution synthesis of Ge nanocrystals from $\mathrm{GeO}_{2}$ powders," CrystEngComm, vol. 13, no. 11, pp. 3674-3677, 2011.

[21] D. A. Ruddy, J. C. Johnson, E. R. Smith, and N. R. Neale, "Size and bandgap control in the solution-phase synthesis of nearinfrared-emitting germanium nanocrystals," ACS Nano, vol. 4, no. 12, pp. 7459-7466, 2010.

[22] S. C. Codoluto, W. J. Baumgardner, and T. Hanrath, "Fundamental aspects of nucleation and growth in the solution-phase synthesis of germanium nanocrystals," CrystEngComm, vol. 12, no. 10, pp. 2903-2909, 2010.

[23] E. Muthuswamy, A. S. Iskandar, M. M. Amador, and S. M. Kauzlarich, "Facile synthesis of germanium nanoparticles with size control: microwave versus conventional heating," Chemistry of Materials, vol. 25, no. 8, pp. 1416-1422, 2013.

[24] W. Z. Wang, B. Poudel, J. Y. Huang, D. Z. Wang, S. Kunwar, and Z. F. Ren, "Synthesis of gram-scale germanium nanocrystals by a low-temperature inverse micelle solvothermal route," Nanotechnology, vol. 16, no. 8, pp. 1126-1129, 2005.

[25] D. D. Vaughn II, J. F. Bondi, and R. E. Schaak, "Colloidal synthesis of air-stable crystalline germanium nanoparticles with tunable sizes and shapes," Chemistry of Materials, vol. 22, no. 22, pp. 6103-6108, 2010.

[26] J. P. Wilcoxon, P. P. Provencio, and G. A. Samara, "Synthesis and optical properties of colloidal germanium nanocrystals," Physical Review B, vol. 64, no. 3, Article ID 035417, 2001.

[27] E. Fok, M. Shih, A. Meldrum, and J. G. C. Veinot, "Preparation of alkyl-surface functionalized germanium quantum dots via thermally initiated hydrogermylation," Chemical Communications, vol. 10, no. 4, pp. 386-387, 2004.

[28] J. H. Warner and R. D. Tilley, "Synthesis of water-soluble photoluminescent germanium nanocrystals," Nanotechnology, vol. 17, no. 15, pp. 3745-3749, 2006.

[29] S. Prabakar, A. Shiohara, S. Hanada, K. Fujioka, K. Yamamoto, and R. D. Tilley, "Size controlled synthesis of germanium nanocrystals by hydride reducing agents and their biological applications," Chemistry of Materials, vol. 22, no. 2, pp. 482-486, 2010.

[30] D. Carolan and H. Doyle, "Size and emission color tuning in the solution phase synthesis of highly luminescent germanium nanocrystals," Journal of Materials Chemistry C, vol. 2, no. 18, pp. 3562-3568, 2014.

[31] D. Carolan and H. Doyle, "Efficient one-pot synthesis of monperse alkyl-terminated colloidal germanium nanocrystals," Journal of Nanoparticle Research, vol. 16, no. 12, 2014.

[32] J. Eastoe, M. J. Hollamby, and L. Hudson, "Recent advances in nanoparticle synthesis with reversed micelles," Advances in Colloid and Interface Science, vol. 128-130, pp. 5-15, 2006.

[33] K. Holmberg, "Surfactant-templated nanomaterials synthesis," Journal of Colloid and Interface Science, vol. 274, no. 2, pp. 355364, 2004.

[34] M. Rukhadze, M. Wotocek, S. Kuhn, and R. Hempelmann, "Influence of anions of the Hofmeister series on the size of $\mathrm{ZnS}$ nanoparticles synthesised via reverse microemulsion systems," in UK Colloids 2011, V. Starov and P. Griffiths, Eds., pp. 67-72, Springer, Berlin, Germany, 2012.

[35] B. Ghosh, Y. Sakka, and N. Shirahata, "Efficient green-luminescent germanium nanocrystals," Journal of Materials Chemistry A, vol. 1, no. 11, pp. 3747-3751, 2013. 
[36] K. Linehan and H. Doyle, "Size controlled synthesis of silicon nanocrystals using cationic surfactant templates," Small, vol. 10, no. 3, pp. 584-590, 2014.

[37] M. Dasog, Z. Yang, S. Regli et al., "Chemical insight into the origin of red and blue photoluminescence arising from freestanding silicon nanocrystals," ACS Nano, vol. 7, no. 3, pp. 2676-2685, 2013. 

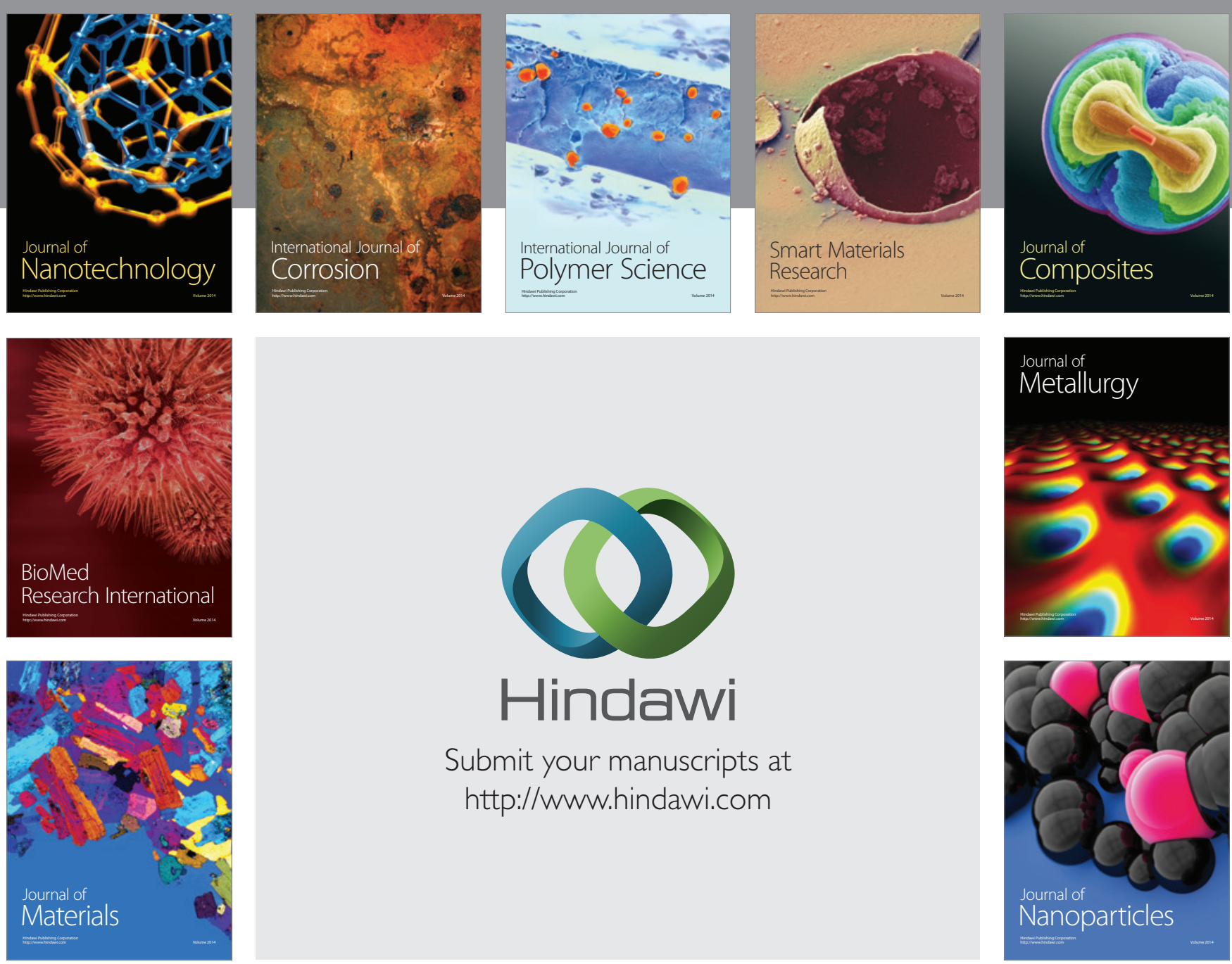

Submit your manuscripts at http://www.hindawi.com
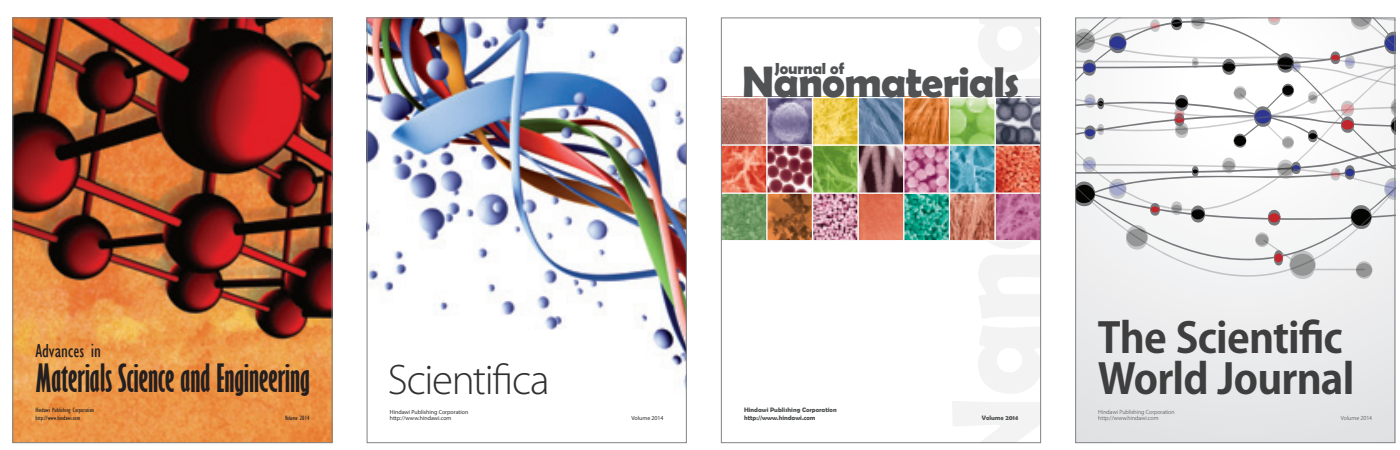

\section{The Scientific World Journal}
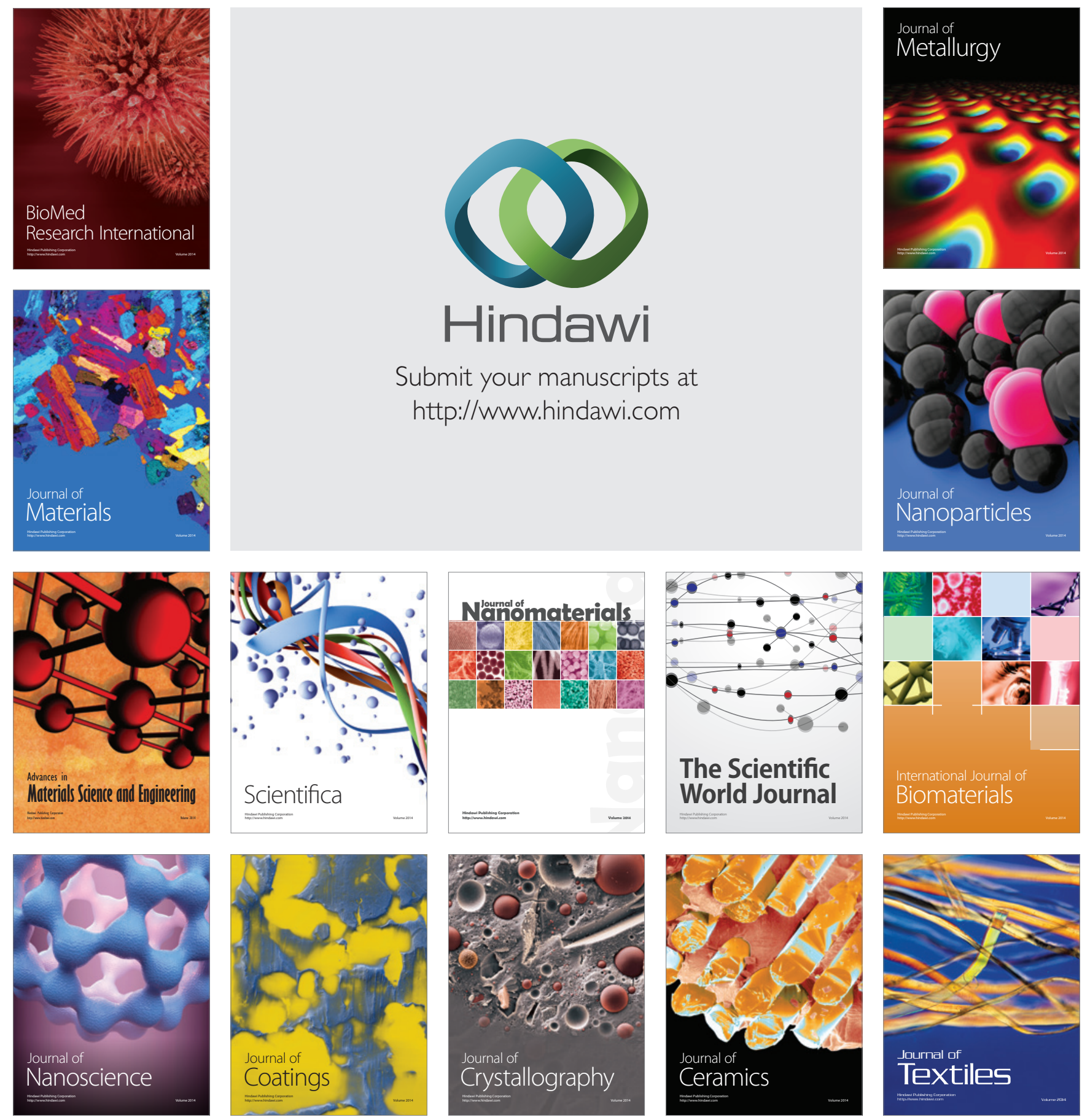